\title{
A Comparative Analysis (SWOT) of Technical Intervention Plans Carried Out in Sistani House and Payambar Mosque of Bam Citadel
}

\author{
Jafar Rouhi* \\ Ph.D. Student at University of Naples Federico II, Italy \\ Email: roouhy@yahoo.com \\ Aldo Aveta \\ Prof. Ing. at University of Naples Federico II, Italy \\ Email: aldo.aveta@unina.it \\ Bianca Gioia Marino \\ Prof. Arch. at University of Naples Federico II, Italy \\ Email: bianca.marino@unina.it
}

Doi:10.5901/mjss.2017.v8n1p431

\section{Abstract}

The Payambar Mosque and Sistani House are two best-preserved monuments of Bam citadel, which suffered severe destruction by the 2003 Bam earthquake. After Bam earthquake, as a part of the national and international efforts for reconstruction of some of the key properties of Bam Citadel, the Iranian experts from RPBCH and Dresden Technical University of Germany, respectively have contributed comprehensive intervention plans for Payambar Mosque and Sistani House. The central idea of these two proposed plans were to find a sensitive balance between the demands of the two adobe world cultural heritage properties and the demands of modern retrofitting techniques in an area with high seismic activity. However, each group through using some new technical methods, which had similarity in manners and differences in employed materials, tried to meet the stability of these adobe monuments. Since by performing a SWOT analysis between the related projects or intervention plans with a common goal, looking at their strengths, weaknesses, opportunities and threats, we can compare the results, it would help us to know which procedure can be considered as an ideal method for similar projects in the future. Therefore, in this paper, to get a better insight about the effectiveness of those intervention plans implemented, a comparative analysis (SWOT) as an organization's strategic planning tool is considered for comparison scale.

Keywords: Bam Citadel, Payambar Mosque, Sistani House, Intervention Plan, SWOT Analysis

\section{Introduction}

According to UNESCO World Heritage Committee, the International Centre for the Study of the Preservation and Restoration of Cultural Property and the International Council on Monuments, Iran is identified as one of the 10 countries in the world that has the richest cultural and historical significances to offer visitors. Subsequent to the ancient history of Iran, adobe-mud brick buildings with their glorious and sustainable architecture have constituted the majority of construction technique in most urban fabric of the historical cities of the country.

In Iran, the traditional adobe construction technique with extraordinary architecture has been common for a very long time in central Iranian plateau in provinces such as Esfahan, Fars, Kerman, Yazd, etc. These cities are not only celebrated for their diversity of styles and influences, but also for the continuity of their traditions on new building practices. Unfortunately, these types of structures pertaining to their antiquity and vulnerability, commonly in earthquake are presenting asthenic behavior during moderate to strong ground motions, and earthquake is recognized as the greatest threat and challenge to these vulnerable types of structures. In Iran, the seismic weakness of adobe buildings has always been the main subject of excessive destruction in the past earthquakes, the 2003 Bam earthquake and what happened to Bam Citadel and other traditional adobe-mud buildings of the city of Bam bears ample testimony to this fact. Such deficiencies are typically related to heavy weight, low tensile strength, fragile behavior of the materials and improper link between structural elements of an adobe structure. Nevertheless, when the stresses exceed the tensile capacity of 
the adobe walls, shear and flexural stresses will cause them to crack, and more cracking leads to the loss of the monolithic character of the earthen wall (lyer, 2014, p. 2). In this regard, the national monuments and vernacular architectures are exposed to such disasters, and the loss of these outstanding properties would negatively affect the country's cultural significance as sources of information of the past and symbols of identity, as well as their socioeconomic values at local, national, and international levels.

The topic of "Bam and its Cultural Landscape" after 2003 Bam earthquake has been the object of debates in several studies and international conferences over the last two decades. The Sistani House and Payambar Mosque as two main monuments of Bam Citadel had entirely been built in traditional technique by combining mud layers (chineh) and sundried mud bricks (khesht) together with chalk decoration, chalk trim, sieved straw, and mud and straw as predominant coating materials. Despite the results of Dr. Tayyari's annual report from 1994 to 2003 in order to restore and renovate these two monuments, the 2003 Bam earthquake severely damaged them ranging from $70-80 \%$. This indicates that a lack of adequate attention, unsuitable attitude and insufficient mobility both in policy, scientific and research activities have contributed to continuation of such events in Iran. In the meantime, inappropriate activities have already been performed before the earthquake in the citadel as conservation and restoration works demonstrated their non-viability. It should be cited that in Iran, there was no clear regulation for preventive conservation, concerning to the problems of historical heritages against of seismic motions.

After the earthquake, as part of the restoration program of the "Recovery Project for Bam's Cultural Heritage" (RPBCH), a wide range of national and international organizations and universities have had technical and financial assistance in various schemes of activity to restore the citadel, and hand it down to future generation. As a result, the citadel now can be named as an open-air museum with last methods of restoration works for adobe-mud brick structures in the world. As intervention plans were executed, the Sistani-House by Dresden University of Germany and Payambar mosque by Iranian experts from (RPBCH) have been chosen as pilot projects for reconstruction. In these cases, two technical and diverse intervention plans have been implemented for seismic consolidation of the properties, one by using locally available materials (e.g. palm fibers and meshes) and another by applying modern materials (e.g. fiberglass meshes and rods). The aim of the reconstruction of these monuments was to achieve a maximum of fidelity to the original constructions, which not only had to be not limited to the appearance, but had to regard also the structural character, the "microstructure", and especially the traditional building procedure. In the present study, through a SWOT analysis, the prevailing trend is to investigate the capabilities of executed intervention plans, and to explore their seismic strength, compatibility and cost efficiency.

\section{Methodology}

This research is a part of the Author's PhD dissertation regarding analysis and classification of different levels of intervention has been implemented by the co-operation among governmental and non-governmental institutions and associations at national and international levels for rescue of historic adobe monuments in Bam Citadel based on the value, function and status of stability of the structures and remains. It should also be mentioned that in August 2015, the Author had a site visit from Bam Citadel, during which it was tried to provide a complete pictorial report from activities that have been executed on the main monuments of Bam Citadel. Therefore, to find the required data of the study focus groups, in-depth individual interviews and review of primary and secondary sources and documents were employed.

Since during post-earthquake restoration of historic monuments, the relation between respect to their values and seismic upgrading is always on two opposing fronts, and it seems that the traditional technology of restoration cannot afford protection of the citadel against a subsequent earthquake, which might happen in the future. During the restoration of Bam Citadel, tremendous efforts have been made with participant groups to introduce new intervention methods alongside the international recommendation and charters.

Now that the restoration of the main monuments of Bam Citadel is mostly finished, here arise a question regarding "what type of restoration with respect to the authenticity of the historic adobe monuments, seismic stability requirement, and cost-effectiveness can be considered as the pattern for similar cases in the future. Accordingly, to explore the effectiveness of the projects implemented, and to synthesize insights obtained from an internal analysis of the projects' strengths and weaknesses with those from an analysis of external opportunities and threats, in this paper a comparative analysis (SWOT) has been performed between the two most ideal technical intervention plans carried out in Bam Citadel.

\section{The Citadel of Bam and its Conservation History before 2003 Earthquake}

The city of Bam and its cultural landscape as one of the oldest centers of urban life is located in the middle of Iranian 
desert, in the south-east corner of Kerman province. Bam city is 1,161 km away from Tehran (the capital city of Iran) and $185 \mathrm{~km}$ from Kerman (the capital of Kerman province). The citadel of Bam is part of an extensive landscape area on the southern border of the Lut Desert, which with its singular topography and morphology, developed from the ancient city of Bam, which is named "Bam Citadel" or "Arg-e-Bam" in the northeast of the present city. This ancient city, since being intruded during centuries for its strategic location in the Silk Road, can be considered as one of the first foci for the organization of civilization in a multicultural society involving different religions such as Zoroastrian, Jewish, Islamic, Christian (Rouhi, Aveta, and Marino, 2017). The citadel of Bam as an outstanding example of a fortified medieval town is better than those of the most fortified cities in Iran and is particularly magnificent for the longevity of its use, which has kept its traditional architecture and urban fabric in Iranian desert environment not only up to the day they were severely damaged by the 2003 Bam earthquake, but even now. This historical and archeological site before the earthquake is considered to be as the largest extended adobe complex in the world. The Bam Citadel was inscribed on the National Heritage List of Iran with registration No. 519, on 21 March 1956, and is legally under the State's protection and supervision of the Iranian Cultural Heritage Organization (ICHO). Although Bam Citadel was inscribed in the National Heritage List, it did not automatically benefit from a minimum protective measure. At the time of registration by ICHHTO, the minimum and feasible protective zone was considered on a case by case basis, and decided upon by ICHHTO (World Heritage Committee [WHC], 2012). However, the milestone of inscription of Bam Citadel in the national heritage list was fundamental to start the first repairs in 1958 and in 1973, the beginning of a comprehensive restoration of the citadel 'with a different emphasis on conservation measures ranging from preservation to reconstruction' (Mokhtari, and Nejati, 2008).

As the Author personally interviewed Dr. Tayyari (August 2015), the Head of Bam Recovery Project until 2003 about Comprehensive Management Plan of Bam Citadel before earthquake, "the purpose of Bam Citadel's comprehensive plan had not been the complete restoration of the complex. But at least enough repairs should be done to show the citadel in different stages of history and construction. This is why the restoration of main elements of citadel like walls, passages, squares, some special private houses and urban establishments had been fit into this program. In the meantime, an exceptional work was conducted on several monuments, as far as the results were quite praised."

In Bam Citadel, earlier restoration work, although meticulously done, have largely been concerned with architectural surfaces, appearance of the buildings and matching the repairs with the original construction in order to retain integrity and authenticity of the site (Vatandoust, Mokhtari, and Nejati, 2008), but due to lack of any seismic preventive considerations, most of the restored monuments were severely damaged by the earthquake.

\section{Sistani House}

The Sistani House as one of the noblest mansions of Bam Citadel is located in the middle of the citadel. It probably belonged to the Sistani family during the Zand period (1750-1794 AD) (Bam3DCG, 2016). This single storey building occupies an area about $673 \mathrm{~m}^{2}$ (Khakzad, 2011). Access to Sistani House is possible by the main entrance door located almost in the middle of house's western wall. It consists of two independent courtyards in the east and west, which are bordered with "winter rooms" in the north and "summer rooms" in the south. The western courtyard with eleven rooms in its sides was larger than eastern courtyard with four rooms, and access between two courtyards was possible with a low corridor. Because of the security reasons, there were no windows in the outer walls. The characteristic elements of this property were its four-sided windrowers as traditional air-conditioning system.

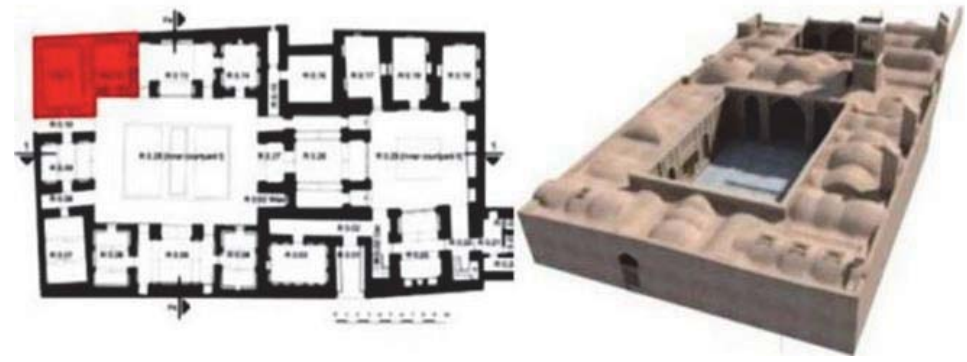

Figure 1. Plan and 3D view from Sistani House of Bam Citadel 
Table 1. Architectural information of Sistani House

Main Original Materials and Construction Techniques: Adobe-mud brick construction technique

Architectural elements Niches, Heater, Under walled arches, Decorative latticework by wood and adobe in openings, Windrowers, Central courtyard and Pool.

The Type of Roofs

Surface Coating Material

Different types of barrel, Dominical and Trought vaults.

Gypsum decoration, Chalk trim, Mud and Sieved Straw and Mud and Straw Plaster.

\subsection{Property Values}

In term of architectural value, Sistani House is one of unique houses within the citadel, which displays several very typical features of traditional Iranian desert dwellings. It has all of typical Persian traditional architectural elements which belong to the upper mediate social level family. Due to its strategic importance location in Bam Citadel, The Sistani House before 2003 earthquake was used as a technical office that served the basement for research and restoration office within the citadel. On the one hand, the location provides the possibilities for the experts to protect and control easily, supervising the restoration project every day and on the other hand, the number of rooms could serve the technical team as an office (Jäger and Fuchs, 2008).

\subsection{Conservation History before Earthquake and Physical Condition after Earthquake}

About conservation history of Sistani House before the earthquake, there is no detailed information, but according to available documents in Document Center of $\mathrm{RPBCH}$, the only known restoration of this building is the one initiated in 1979 and ended in 1995. After 2003 Bam earthquake, this Iranian traditional residence house faced a severe destruction, so most of roofs and walls were completely destroyed. Half of the northern (north towards west) and western sides of the Sistani House faced total collapse, but damages were more slight in other sides.

\subsection{Proposed intervention plan}

As part of the international efforts for reconstruction of some of the key properties of Bam Citadel, the Dresden Technical University of Germany together with Jaeger Consulting Engineers Ltd. contributed in a comprehensive research, restoration and reconstruction plan of the Sistani House. In order to develop a strengthening methodology for Sistani House, two rooms in the northwest corner have been chosen as a pilot project. The central idea of the proposed measures was to find a sensitive balance between the demands of an earthen world cultural heritage site as well as the demands of modern retrofitting techniques preventing in an area of strong seismic activity with the aim to create an earthquake resistant building technology. This project was the result of the conceptual design and the consideration of the pros and cons of the different variants for dealing with the remains (Jäger, Fuchs, and et al., 2007). At first step towards complete rehabilitation of the Sistani House, the project started in the second half of 2006 with material tests for retrofitting technologies which had to guarantee that the buildings will not collapse once more during the next possible earthquake of the same intensity. Therefore, German group began its actual work on the property in the summer of 2007 and finished it in April 2008. Now the work is ongoing by the same method with Iranian experts from RPBCH. The following steps listed below are measures which have been implemented in Sistani House through intervention plan proposed by Dresden University of Germany:

(I) Debris removal: this step was carefully and attentively supervised and organized by staffs of the Dresden University to gather as much information as possible about actual process of the damage typologies and the former layout of the house. As Jäger and Fuchs (2008) noted, "The supervised rubble removal also offered some information about the building history of the Sistani House, as the debris revealed a surprisingly high density of findings integrated into the masonry. A remarkably high number of fragments of ceramic vessels were also found."

(II) Production of reinforced adobe bricks by palm fibers: any new approach in Sistani House had to start from enhancing the capability of adobe building to react flexibly to seismic motion without the immediate loss of coherence. The team of the Technical University of Dresden conducted a wide range of practical tests for improvement of mechanical property of adobe bricks in the laboratories of the Dresden University as well Bam to find best additive material. After running a test row on different materials, it was decided to propose "palm fibers" as suitable material for reinforcing of adobe bricks. Tests have proved a considerable increase in compression and tensile strength of reinforced adobe bricks. The palm fibers have the additional advantage of abundant local availability; palm fibers are a side product of the 
extended date growing gardens as the material is normally simply burned. In this way to prepare palm fibers as additive material to adobe mortar, the thick edge of palm leaves were separated and then the remained softer leaves were cleaned. In the next step, they were cut out to smaller parts for putting inside of machine designed for chopping of palm leaves. Afterwards, the palm fibers were mixed with other ingredients. As mentioned by Jäger \& Fuchs (2008) about the rate of materials' combination, "The results enabled us to name the exact quota of the ingredients clay and sand (70: 30) and fibers ( $0.6 \%$ of the weight of the sand-soil compound)." In this case, according to the statistics presented by RPBCH, over 25000 reinforced adobe bricks with palm fibers for being used in reconstruction operations of Sistani House were produced in Bam Citadel's workshop.

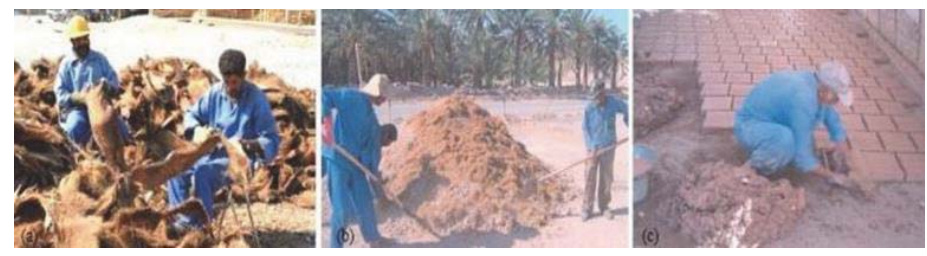

Figure 2. Process of the production of reinforced adobes with palm fiber in Bam Citadel workshop Source: archive of RPBCH, 2008

III) The grouting of cracks: for cracks with less than $2 \mathrm{~cm}$ wide, the operation of injection grouting had been employed. In this case, to reduce the demand of water in mixture and create a paste-like consistency with which the cracks become superficially closed, the grout consisted of some ingredients as cement, lime or fluids added to the mixture such as potassic and sodium water glass and soda. For the performance of this process, a plastic pipe with the diameter of the neck of the injection pump was inserted into the crack in regular intervals of about $25 \mathrm{~cm}$ in order to create openings for the following injection of the grouting suspension. Because of high daily temperature of the region, and to prevent the suspension to dry up quickly, the grouting was only carried out in the early morning and late afternoon. The higher pressure considered for grouting was by using two bars (Jäger and Fuchs, 2008).

(IV) Needling and anchoring: for cracks with larger than $2 \mathrm{~cm}$ wide, the technique of needling and anchoring were applied. The anchors were placed in boreholes and fixed with the chosen grouting material (Jäger and Fuchs, 2008).

(V) Reinforcement of walls vertically: at first, for the reinforcement of walls in Sistani House, fiberglass rods had to be inserted vertically. To this end, scaffolding was installed alongside the walls upon which the core-drilling machine for the vertical boreholes was mounted. These were drilled in an interval of about $100 \mathrm{~cm}$ with a width of $10 \mathrm{~cm}$, which reached down to depth of $1.5 \mathrm{~m}$ below ground level. The vertical anchors consisted of three glass fiber rods with a diameter of $8 \mathrm{~mm}$. On their lower end, the bundle of three rods was spliced up; it was inserted into a block of fine concrete that tied the vertical anchor to the ground. The rest of the borehole was filled with the same clay suspension that was used for the grouting in the consolidation phase. The vertical anchors reach up to the highest parts of the walls (Jäger and Fuchs, 2008).

(VI) Reinforcement of walls horizontally: in this case, every $0.50 \mathrm{~m}$ in height, a layer of fiberglass mesh was inserted into the horizontal joint in the masonry. In addition to that, a horizontal rod of fiberglass was fixed to the vertical anchors (Jäger and Fuchs, 2008).

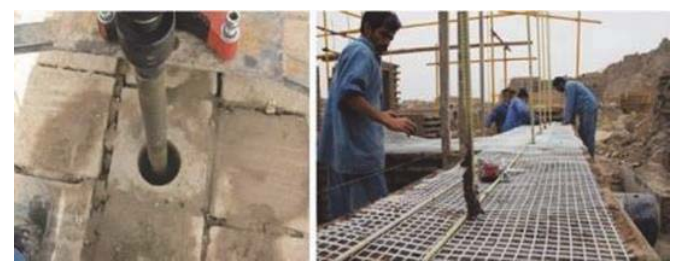

Figure 3. (Left) drilling of adobe wall for insertion of fiberglass rods; and (Right) placement of fiberglass mesh on the wall (Source: archive of RPBCH, 2008).

(VII) Increasing roofs fixed end and wall through the installation of ring beams: inserting ring beams is among the 
methods of stabilization that can have positive effects on the seismic resistance of earthen structures while preserving their integrity. These ring beams are located under the floor, as shown in figure 4. On the height of the impost of the vaults, a ring beam composed of six fiberglass rods (width $0.60 \mathrm{~m}$, height $0.30 \mathrm{~m}$ ) is constructed and bricked up (Jäger and Fuchs, 2008). Specific elements, including glass fibers and mud grout compatible with the old parts of the wall, are inserted into these beams for reinforcement (Vatandoust et al., 2008).

(VIII) Reinforcement of roofs: to improve the inner integrity of the roofs, it was decided to wrap the transversal arches as well as the sectroids of the vault with the same fiberglass that has been used for the horizontal joints. Then, the traditional adobe surface coating covered the meshes.

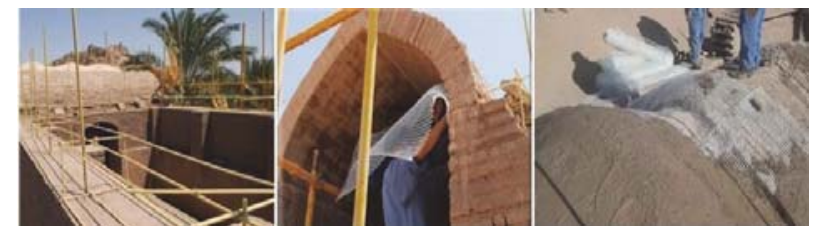

Figure 4. Increasing the integrity of roofs and walls by ring beam and stabilizing inner and outer parts of roofs in Sistani House with installing fiberglass mesh (Source: archive of RPBCH, 2008).

Table 2. The SWOT analysis related to Sistani House
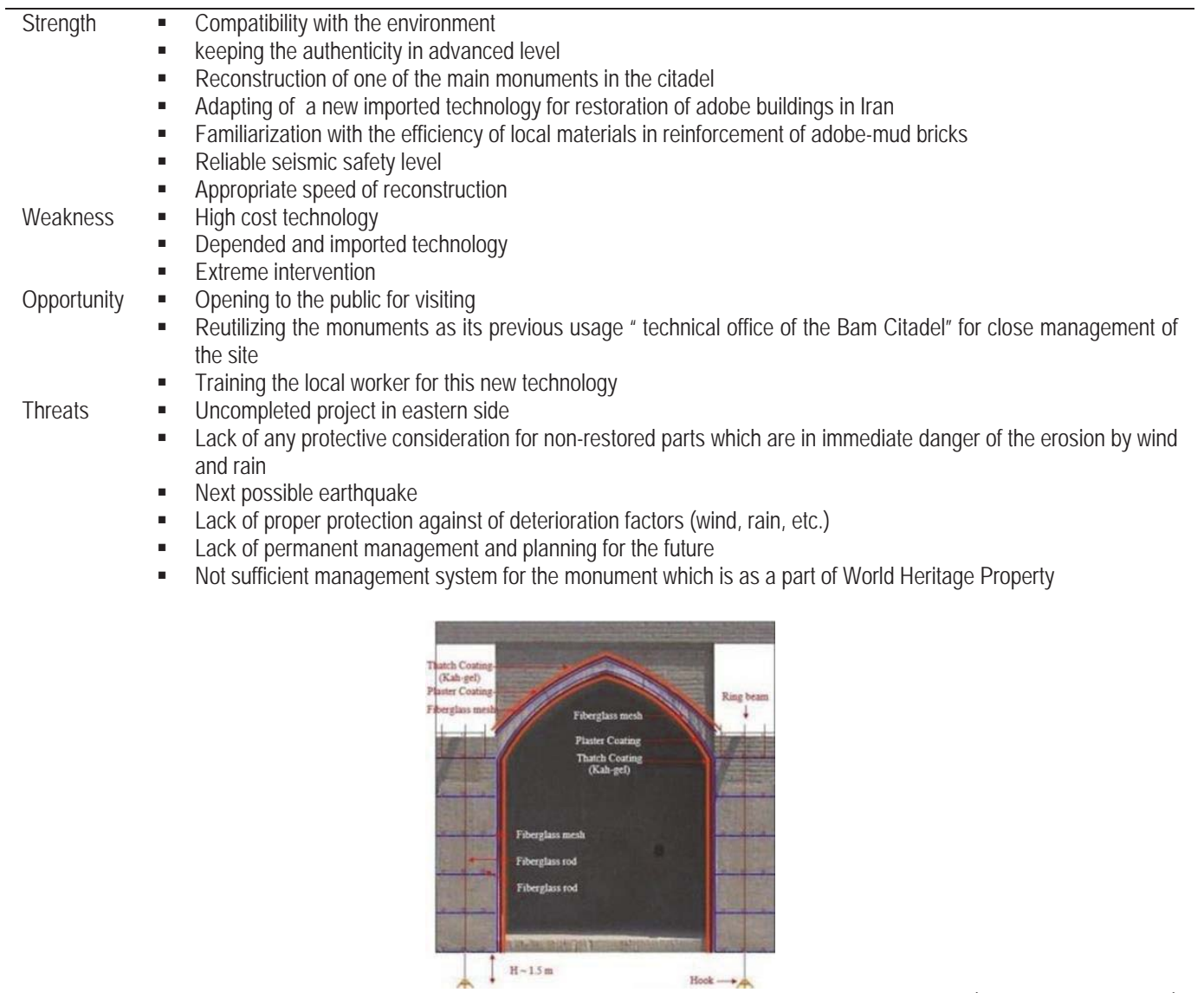

Figure 5. Schematic view from intervention plan implemented in the Sistani House of Bam Citadel (Designed by Author). 


\section{Payambar Mosque}

The primary archaeological theory indicates that Payambar Mosque was a part of a bigger mosque such as the JaameMosque south east of the Citadel. More documents and records are needed to approve this theory (Mokhtari, Nejati, Shad, and Khatooni, 2008). This small mosque is located at the end of Bazaar's north-west, in front of Sistani House. There is an altar in the western side of mosque which dates back to the Safavid period (1501-1736 AD). The area of Payambar Mosque is around $128 \mathrm{~m}^{2}$ in a trapezoidal cross-section. Because of the distance between Bazaar and Friday Mosque, this small vestry in the past was regularly used to pray by the traders and passengers. However, the erratic parts in the process of fabrics design made evolution in the area, this special instance has survived originally during the past years (Mokhtari et al., 2008). As photos before earthquake show, it can be seem that to enter the Mosque, there were two doorways which both opened in the northern side of the property, one for males and another for females. The internal space of Payambar Mosque can be divided into two sections, one bigger than the other: the big one with a column in its center was probably used by males and small one was used by females, and the spaces between the two halls is linked by a under-walled arch.
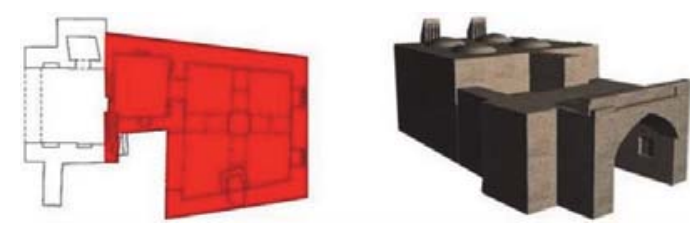

Figure 6. Plan and 3D view from Payambar Mosque of Bam Citadel

Table 3. Architectural Information of Payambar Mosque

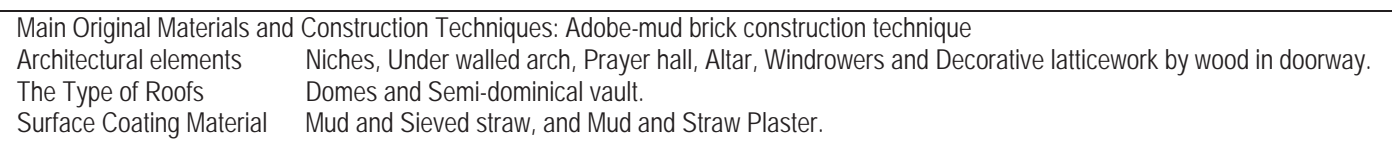

\subsection{Property Values}

This Mosque with its simple architectural elements gives a strong sense of spirituality to its visitors. By the development of Islam and the increase in the number of Muslim who entered the citadel for trading in the Bam's ancient Bazaar, and also because of the long distance between Bazaar and Friday Mosque, the need to build new Mosque in the vicinity of the Bazaar and Caravanserai was felt. In fact, the Payambar Mosque of Bam Citadel with its small size was built to meet the above-mentioned necessities.

\subsection{Conservation History before Earthquake and Physical Condition after Earthquake}

There is no precise report regarding the previous conservation activities of the Payambar Mosque before the earthquake. In this case, I have just found a picture that shows the intervention works in process in 1990. The Payambar Mosque was severely destroyed during the 2003 earthquake. Through the earthquake, this monument sustained damages more than the other buildings; all the western and northern parts of the property were fully destructed. The central column of the Mosque, which suffered all of loads transferred by four domed shape roofs could withstand by cracks in its lower part, but the domes were completely shattered. 


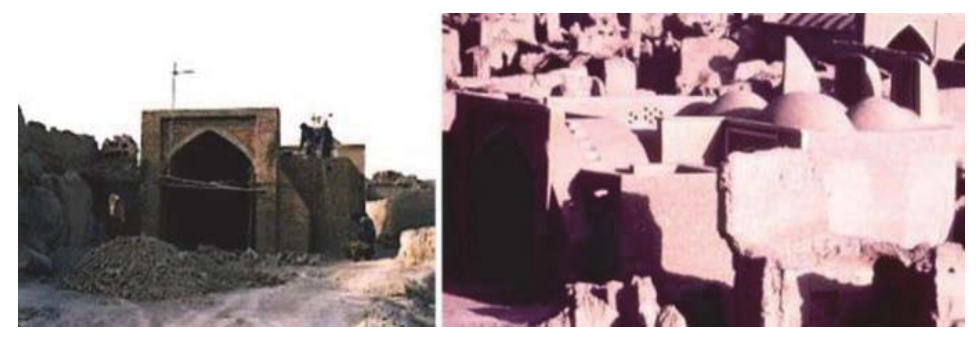

Figure 7. (Left) restoration activities in Payambar Mosque of Bam Citadel (Source: archive of the RPBCH, 1990); and (Right) view from Payambar Mosque before earthquake (photo by Louyot, 2003)

\subsection{Proposed intervention Plan}

The intervention plan of Payambar Mosque that was proposed by Iranian experts form RPBCH can be known as the best example for simultaneous use of engineering restoration outcome and traditional restoration knowledge. The central focus on intervention plan of Payambar Mosque was inspired from experiences acquired from previous intervention pilot projects in other monuments of Bam Citadel, such as Tekiyeh, Bazaar, Sistani House and Barrack. So far, a special attention has been dedicated to traditional methods by using local materials (palm fibers and palm meshes). The concern in this technique was the seismic loads of the dominant force for destruction of adobe-mud brick properties that would be reduced. During reconstruction phase, to keep the authenticity and integrity of the property, the damaged parts of the mosque had been reconstructed based on the original location of the walls extracted from available documents and ruins remained after the earthquake. The following steps listed below are measures which have been implemented in Payambar Mosque through intervention plan proposed by Iranian group:

(I) Debris removal: in each monument of Bam Citadel, in parallel to debris removal all works have been operated by supervision of archeologists. After removal of the debris, the archaeologists started the excavation and found that there were causeway, catch basin and clay pipe in the $80 \mathrm{~cm}$ lower than the ground level, which were buried and prevented up to now. According to the archaeological investigations, it might have been built under the remains of early construction (Mokhtari et al., 2008).

(II) Strengthen of walls with simple traditional measures: at first, after replacement of some kinds of deteriorated adobe bricks, to meet specific structural inadequacies, the thickness of walls in some areas that were vulnerable to the forces of the seismic loads was to be increased.

(III) Reinforcement of walls vertically: to provide any required bending resistance in the monument, the structure was connected to the ground with some innovative method by embedding local tension elements "palm fibers". The figure 8 exactly shows the details of drilling procedures by halter for inserting vertical elements to the foundation soils at depths of $150 \mathrm{~cm}$. In this case, vertical elements were installed along a certain line by maximum distance of around $110 \mathrm{~cm}$ that is reduced to $60 \mathrm{~cm}$ in the compulsory points at the center of main walls.

(IV) Reinforcement of walls horizontally: on the other hand, to provide shear resistance in the structure, the natural horizontal elements produced by local producers "palm mesh" was to be inserted as tension elements from within thickness, by going towards upper parts of the wall, the palm meshes used between brick lines were decreased (figure 7). Meanwhile, to install natural fibers between rows of adobe bricks, a simple tool was used to stretch the meshes during their operation.

(V) Increasing roofs fixed end and wall through the installation of ring beams: by copying from intervention plan executed in Sistani House, the same method which was used for increasing the junction between walls and roofs in Sistani House had been employed in Payambar Mosque of Bam Citadel.

(VII) Reinforcement of roofs: after doing all of the above-mentioned steps, to reinforce and to increase the integration of roofs, a layer of palm mesh was wrapped out on outer surface of roofs. Meanwhile before setting up palm meshes, the roofs were sewed out by palm fibers. At the end, the traditional clay-and-straw mortar plaster (Kah-gel) was used to cover the palm meshes. 

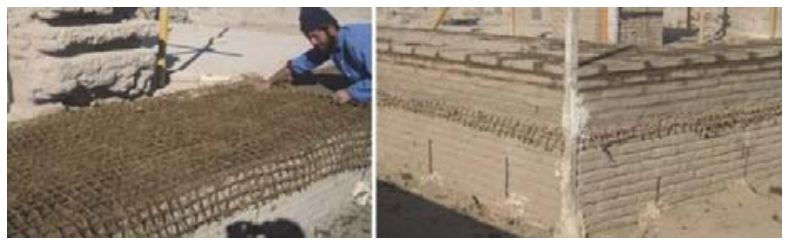

Figure 7. The process of Palm mesh insertion between layers of adobe-wall in Payambar Mosque (Source: RPBCH, 2008).

Table 4. SWOT analysis related to Payambar Mosque
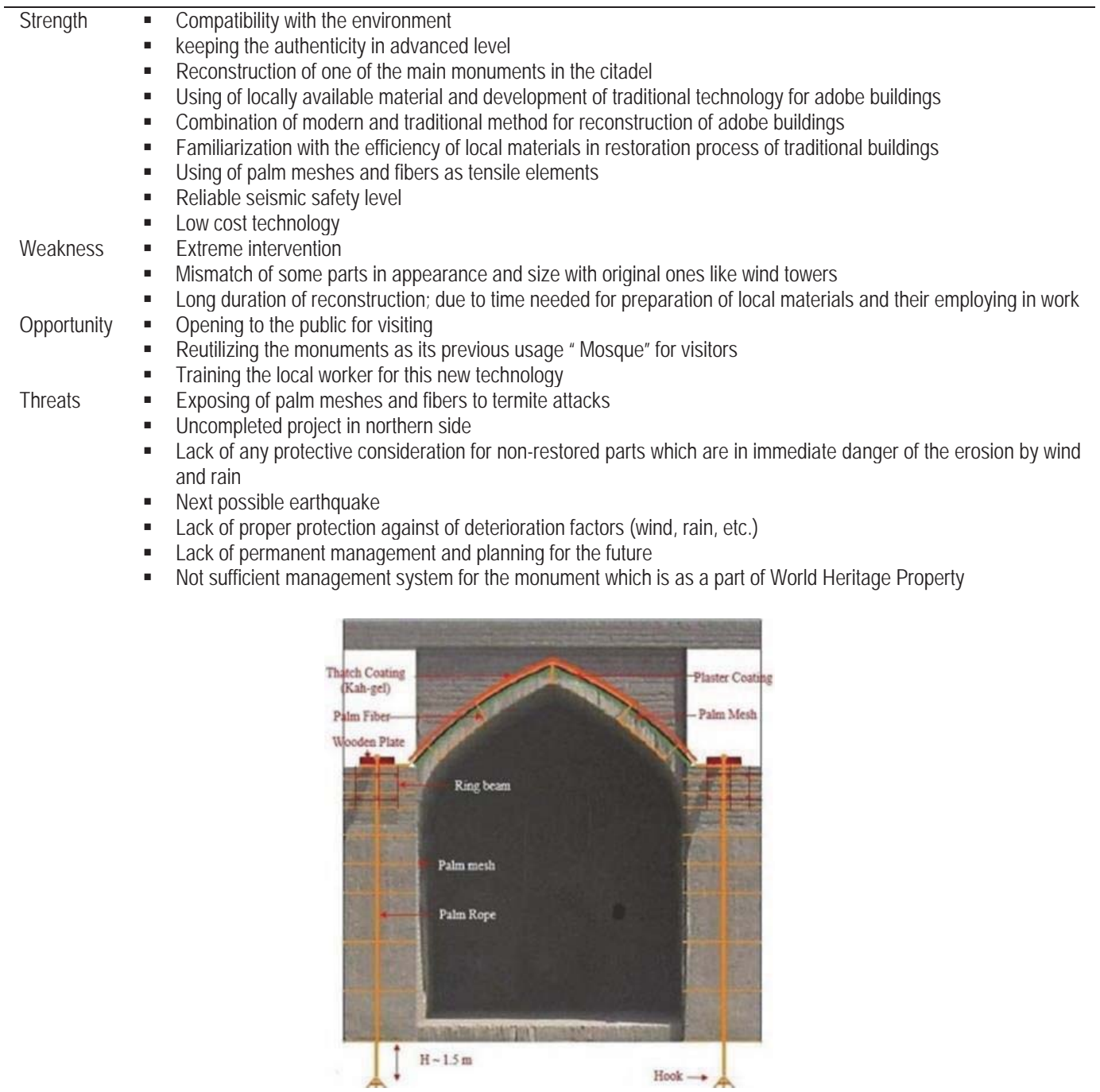

Figure 8. Schematic view from intervention plan implemented in the Payambar Mosque of Bam Citadel (Designed by Author). 


\section{Conclusion}

In Payambar Mosque and Sistani House like other properties of Bam Citadel, most of the interventions before the earthquake were limited to superficial restoration. Since in the technical restoration and reconstruction of these two monuments before the earthquake, seismic effects as a possible threat had not been considered; as a result, both the historical remains of the monuments and particularly their renowned and reconstructed parts were incapable to provide necessary stability to endure the main seismic motion of the 2003 earthquake. This error, in its turn, by causing further destructions of the monuments showed that the traditional methods of adobe's restoration need strict attention, thorough analysis and scientific upgrading. In Payambar Mosque and Sistani House, the proposers of intervention plans based on a particular cautiousness and a comprehensive view from factors which have impact on seismic endurance of the monuments proposed their intervention plans. Because of SWOT analysis conducted on each of these plans and with respect to the authenticity of the monuments, they were able to meet their seismic resistance. However, in decision to select one of these two methods for similar projects, other various factors like durability, cost efficiency and time required are implicated. In these cases, the Sistani House's intervention plan has more durability and has more time saving, while the intervention plan of Payambar Mosque has much more cost efficiency. Therefore, depending on the condition prevailing of the sites and projects, the importance of properties, options available and financial aspects, each of these plans can be considered as a model for future approaches. In overall, in cases like Bam Citadel, due to shortage of funds and the large extent of reconstruction required, the model of Payambar Mosque can be considered as the best convenient technique for restoration and reconstruction of the remaining monuments.

\section{References}

Bam3DCG. (2016). Virtual 3D Reconstruction of Bam Citadel. Retrieved from http://dsr.nii.ac.jp/Bam3DCG

Iyer, N.L. (2014). Performance Evaluation of Clay Grout Formulations for Structural Cracking in Historic Earthen (Mud Brick) Buildings (Master's Thesis), University of Pennsylvania, Philadelphia, PA. Retrieved from http://repository.upenn.edu/hp_theses/561

Jäger, W., \& Fuchs, C. (2008). Reconstruction of the Sistani House at Bam Citadel after the collapse due to the earthquake 2003. In: Dina D'Ayala, D., \& Fodde, E. (eds.), Structural Analysis of Historic Construction: Preserving Safety and Significance, Two Volume Set Proceedings of the $6^{\text {th }}$ International Conference on Structural Analysis of Historic Construction, SAHC08, 2-4 July 2008, Bath, United Kingdom.

Jäger, W., Fuchs, C., \& et al. (2007). Final report for a rehabilitation concept for Sistani House, Bam Citadel (Iran). Worked out for UNESCO Japan Funds-in-Trustfor the Bam Emergency Technical Co-operation 2004-2007, Research Organization for Cultural Heritage and Tourism (ROCHT), Iranian Cultural Heritage and Tourism Organization (ICHTO) by Jäger Consulting Engineers Ltd. Radebeul.

Khakzad, S. (2011). Site Conservation Assessment: Bam and its Cultural Landscape. Catholic University of Leuven, Global Heritage Fund 2011. Retrieved from ghn.globalheritagefund.com/uploads/documents/document_1778.pdf

Mokhtari, E., \& Nejati, M. (2008). The Restoration of Bam Citadel, Iran - new approaches. LEHM 2008, The $5^{\text {th }}$ International Conference on Building with Earth. Weimar: Dachverband Lehm e.V.

Mokhtari, E., Nejati, N., Shad, S., \& Khatooni, N. (2008). Restoration Plan of Pyambar Mosque in Bam Citadel (Arg e Bam). In: Proceedings of $14^{\text {th }}$ World Conference on Earthquake Engineering (WCEE), Beijing, China.

Rouhi, J., Aveta, A., \& Marino, BG. (2017). The Influence of Iranian Islamic Architecture on the Jewish House (West Sabat House) of Bam Citadel, The Proceedings of the International Conference on Islamic Heritage Architecture and Art (Islamic Heritage Architecture 2016), International Journal of Heritage Architecture, WIT Press; 1(1): 89-98.

Vatandoust, R., Mokhtari, E., \& Nejati, M. (2008). Consolidation and Reinforcement of Destabilized Earthen Structures in Bam after the Earthquake of December 2003: Some New Approaches. In: Rainer, L., Rivera, A.B, Gandreau, D. (eds.), Terra 2008: The 10 th International Conference on the Study and Conservation of Earthen Architectural Heritage. Bamako, Mali: The Getty Conservation Institute.

WHC. (2012). The World Heritage Property of Bam and Its Cultural Landscape (Islamic Republic Of Iran). Report on the Joint World Heritage Centre / ICOMOS Reactive Monitoring Mission, 16-22 October 2011, Paris. Retrieved from whc.unesco.org/document/116542 